\title{
Influence of Nitrogen Sources on Glycogen Metabolism in Saccharomyces carlsbergensis
}

\author{
By J. U. BECKER*, M. I. SHEHATA AND S. M. MIZANI \\ Botanisches Institut der Universität Bonn, Kirschallee 1, D-5300 Bonn 1, \\ Federal Republic of Germany
}

(Received 23 June 1981; revised 30 July 1981)

Storage of glycogen in yeast (Saccharomyces carlsbergensis) cells was strongly suppressed by the presence of nitrogen sources. Peptone initiated glycogen breakdown within minutes. This effect could not be duplicated with ammonium ions alone nor with single amino acids or mixtures of a few amino acids, but it could be duplicated by the addition of all the amino acids in the molar ratios found in casein. If fewer amino acids were supplied, glycogen was initially synthesized but then depleted after $30-60 \mathrm{~min}$ at $28{ }^{\circ} \mathrm{C}$, the time being shorter for more easily utilized amino acids. In the presence of glucose, dinitrophenol $\left(10^{-4} \mathrm{M}\right)$ slowed down or inhibited glycogen synthesis, but it did not initiate glycogen breakdown in the absence of glucose. Energy charge and the concentrations of adenylates and UDP-glucose were not significantly different in the presence and absence of peptone; pyruvate accumulated under the former condition. No turnover of glycogen was observed during glycogen synthesis, pointing to an effective regulation of glycogen metabolism via an unknown mechanism.

\section{INTRODUCTION}

Glycogen is a major storage product in yeast, enabling the cells to survive long starvation periods. The glycogen content of the cells changes drastically in response to physiological state. For example, during sporulation the cells first synthesize and then degrade glycogen (Fonzi et al., 1979); in continuous culture, glycogen content depends on the growth rate (Küenzi \& Fiechter, 1972). Glycogen synthesis initiated during transition of a batch culture of Saccharomyces cerevisiae (Rothman \& Cabib, 1969) or S. carlsbergensis (Becker et al., 1979) to growth is probably caused by nutrient depletion (Lillie \& Pringle, 1980). By contrast, stationary phase cells of an inoculum rapidly degrade glycogen after transfer to media in which growth is limited by either nitrogen or carbohydrate content (Becker et al., 1979). Since in these cases depletion of glycogen takes place in the presence of a high concentration of glucose, other factors present in the medium must initiate the breakdown. In this paper, the nature of these factors is explored and some of their possible modes of action are investigated.

\section{METHODS}

Growth and preparation of yeast. The experiments were initiated with an inoculum of stationary phase cells of Saccharomyces carlsbergensis (ATCC 9080) obtained from cultures grown aerobically under carbohydratelimited conditions for $24 \mathrm{~h}$ at $28^{\circ} \mathrm{C}$ (Becker et al., 1979) yielding $22 \pm 1 \mathrm{~g}$ yeast $\mathrm{l}^{-1}$. The cells were harvested by centrifugation at $3000 \mathrm{~g}$ for $5 \mathrm{~min}$, washed twice in cold basic medium (see below) and finally suspended as a $2 \%$ $(w / v)$ suspension in cold media as specified in the experiments described. The wet weight of the cells after centrifugation serves as the basis for the cell concentration in the suspensions. The suspension was first kept in ice for $20-40 \mathrm{~min}$ and then incubated in a water bath at $28^{\circ} \mathrm{C}$ for $10 \mathrm{~min}$. The experiments were started by the addition of $100 \mathrm{~mm}$-D-glucose. 
Determination of glycogen and metabolites. Samples $(2 \mathrm{ml})$ were withdrawn and injected into $1 \mathrm{ml} 15 \%(\mathrm{w} / \mathrm{v})$ trichloroacetic acid to stop metabolism rapidly. After $20-80 \mathrm{~min}$ on ice, the cells were centrifuged; glucose was determined enzymically in the supernatant (Bergmeyer, 1974), and glycogen content was assayed in a portion of the cell pellet suspended in $0.25 \mathrm{M}-\mathrm{Na}_{2} \mathrm{CO}_{3}$ (Becker, 1978).

Metabolites were determined enzymically according to Bergmeyer (1974). UDP-glucose was assayed with UDP-glucose dehydrogenase (EC 1.1.1.22), pyruvate with lactate dehydrogenase (EC 1.1.1.27), ATP with hexokinase (EC 2.7.1.1) and glucose-6-phosphate dehydrogenase (EC 1.1.1.49), and ADP and AMP with pyruvate kinase (EC 2.7.1.40), lactate dehydrogenase and myokinase (adenylate kinase; EC 2.7.4.3). For extraction of metabolites trichloroacetic acid was replaced by perchloric acid $(15 \%, \mathrm{w} / \mathrm{v})$. The cells were extracted for $15 \mathrm{~min}$ at room temperature with occasional shaking. Pyruvate was determined immediately in the supernatant after neutralization with buffered $\mathrm{KOH}$ (Becker, 1978). The remaining supernatant was frozen in small samples for later enzymic analysis. Repeated freezing and thawing led to low recoveries of UDP-glucose. For glycogen determination in these cells, the perchloric acid was removed from the cell residues by two water washes prior to suspension in carbonate solution.

Determination of glycogen turnover. Cells were washed twice with $50 \mathrm{~mm}$-potassium phosphate buffer, $\mathrm{pH} 4 \cdot 6$, aerated for $4 \mathrm{~h}$ at $28^{\circ} \mathrm{C}$ to decrease the glycogen concentration and centrifuged. They were resuspended $(5 \%$, $\mathrm{w} / \mathrm{v})$ in the same buffer. After $10 \mathrm{~min}$ aeration at $28^{\circ} \mathrm{C}, 20 \mathrm{~mm}-\mathrm{D}-\left[\mathrm{U}-{ }^{14} \mathrm{C}\right] \mathrm{glucose}\left(21000 \mathrm{~d} . \mathrm{p} . \mathrm{m}\right.$. $\left.\mu \mathrm{mol}^{-1}\right)$ was added and the cells were incubated for $20 \mathrm{~min}$. They were spun down $(3000 \mathrm{~g}, 2 \mathrm{~min}$ ), washed in $50 \mathrm{~mm}$ potassium phosphate buffer, then resuspended in the original volume of the buffer and aerated. To one half of the suspended cells, $100 \mathrm{~mm}$ unlabelled glucose was added, while the second half was only aerated. At intervals samples were withdrawn, extracted with trichloroacetic acid and washed once with the solution. The cell residues were suspended in $0.25 \mathrm{M}-\mathrm{Na}_{2} \mathrm{CO}_{3}$, kept in a boiling water bath for $90 \mathrm{~min}$, spun down, and washed once with the same solution and twice with $0.2 \mathrm{M}$-sodium acetate buffer, $\mathrm{pH} 4.8$. This treatment dissolves only $5-10 \%$ of the glycogen. Samples were incubated with amyloglucosidase; in blanks the enzyme was omitted. In the supernatant the concentration (enzyme assay) and radioactivity (liquid scintillation counting) of the glucose liberated were determined.

Media and chemicals. Basic medium was the semi-synthetic medium used for culturing the cells (Gosh et al., 1960 ) but without nitrogen sources and glucose. It contained the following (per litre): $\mathrm{KH}_{2} \mathrm{PO}_{4}, 0.55 \mathrm{~g} ; \mathrm{KCl}$, $0.42 \mathrm{~g} ; \mathrm{MgSO}_{4} .7 \mathrm{H}_{2} \mathrm{O}, 0.125 \mathrm{~g} ; \mathrm{CaCl}_{2} .2 \mathrm{H}_{2} \mathrm{O}, 0.125 \mathrm{~g} ; \mathrm{FeCl}_{3} .6 \mathrm{H}_{2} \mathrm{O}, 1.25 \mathrm{mg} ; \mathrm{MnSO}_{4} . \mathrm{H}_{2} \mathrm{O}, 2.50 \mathrm{mg}$; myo-inositol, $10.00 \mathrm{mg}$; calcium pantothenate, $3.50 \mathrm{mg}$; pyridoxal. $\mathrm{HCl}, 0.25 \mathrm{mg}$; thiamin. $\mathrm{HCl}, 0.25 \mathrm{mg}$; biotin, $0.03 \mathrm{mg}$. The $\mathrm{pH}$ was adjusted to 5.0 with $5.0 \mathrm{~g}$ tripotassium citrate. $\mathrm{H}_{2} \mathrm{O}$ and titration with citric acid. Complete

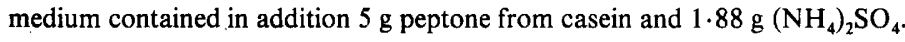

All chemicals were of analytical purity. Radioactive glucose was a product of Amersham-Buchler, Braunschweig, F.R.G. Peptone from casein was obtained from Serva Feinbiochemica, Heidelberg, F.R.G., and enzymes and cofactors were from Boehringer. For all solutions, glass-distilled water was used.

\section{RESULTS AND DISCUSSION}

\section{Influence of nitrogen sources on glycogen metabolism}

The glycogen breakdown in the cells of the inoculum after transfer to complete medium (cf. Becker et al., 1979) is likely to be initiated by one or more components of the medium. We conducted a systematic search to identify these components.

As shown in Fig. 1, cells synthesized glycogen in the basic medium. Typically, a 2\% suspension of the cells accumulated glycogen at a rate of $0.5-1.5 \mu \mathrm{mol}$ glucosyl units $(\mathrm{g}$ yeast $)^{-1} \min ^{-1}$ at $28^{\circ} \mathrm{C}$ in the absence of all nitrogen sources. In the presence of 55 mM-ammonium sulphate, the rate of glycogen synthesis was initially lowered by a factor of about 3, an effect previously observed (Becker et al., 1979). Only after $2 \mathrm{~h}$ was glycogen broken down. By contrast, in the presence of peptone, whether in the absence or the presence of ammonium sulphate, glycogen breakdown was initiated within $5 \mathrm{~min}$ or less. Thus, we further investigated the effect of peptone. This nutrient is rather ill-defined: it consists mainly of a mixture of amino acids and small peptides, all of which could have been responsible for the effect of peptone. First, single selected amino acids were tested for their ability to induce immediate glycogen breakdown. Glutamic acid, aspartic acid, glutamine, asparagine and lysine, each at concentrations of 25,50 and $75 \mathrm{mM}$, were added to the basic medium. In no case was glycogen breakdown initiated immediately, even if the cells were preincubated at $28{ }^{\circ} \mathrm{C}$ with the amino acid prior to the addition of glucose. Under the latter condition, 


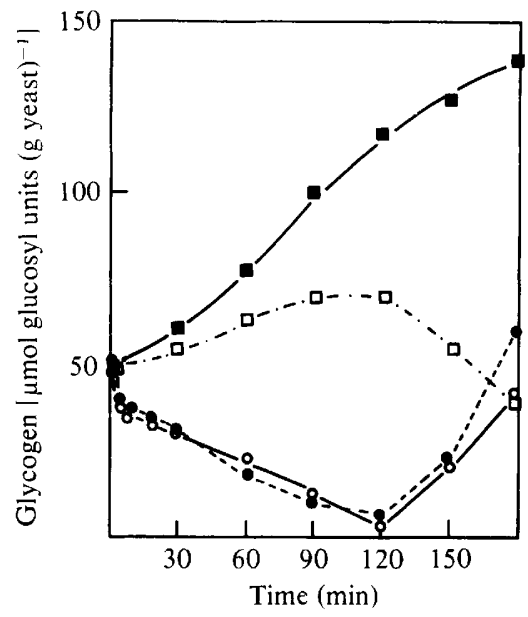

Fig. 1

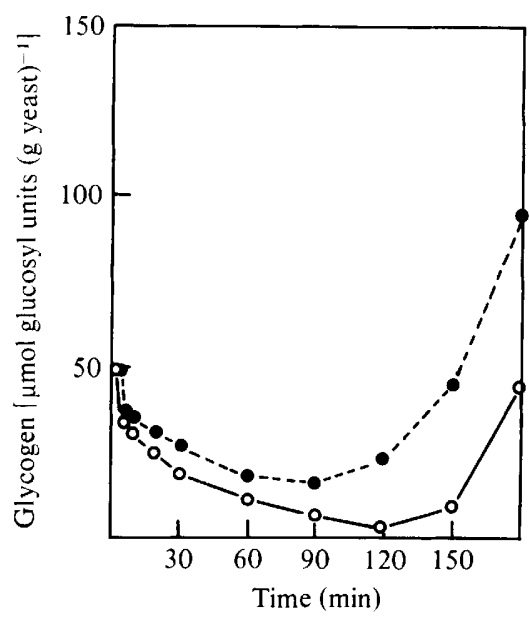

Fig. 2

Fig. 1. Glycogen synthesis and breakdown in Saccharomyces carlsbergensis cells in the absence and presence of nitrogen sources. Cells were incubated in basic medium ( $\square$ ), basic medium with 55 $\mathrm{mM}-\left(\mathrm{NH}_{4}\right)_{2} \mathrm{SO}_{4}(\square)$, complete medium (basic medium with $5 \mathrm{~g}$ peptone and $\left.1.88 \mathrm{~g}\left(\mathrm{NH}_{4}\right)_{2} \mathrm{SO}_{4}\right)(\mathrm{O})$ or complete medium without $\left(\mathrm{NH}_{4}\right)_{2} \mathrm{SO}_{4}(\mathrm{O})$. The glucose consumption rate was $21 \pm 3 \mu \mathrm{mol}$ glucose $\min ^{-1}$ (g yeast) $)^{-1}$ in all runs. Increased budding occurred after $1 \mathrm{~h}$ in all cases, but significant growth was observed only in the batches with nitrogen, after $3 \mathrm{~h}$.

Fig. 2. Glycogen metabolism in $S$. carlsbergensis cells in the presence of an amino acid mixture $(0.22 \%)$ in the molar ratio of casein. The cells were incubated in basic medium containing all the amino acids specified in the legend to Fig. 3, either with (O) or without (O) ammonium sulphate (55 mM).

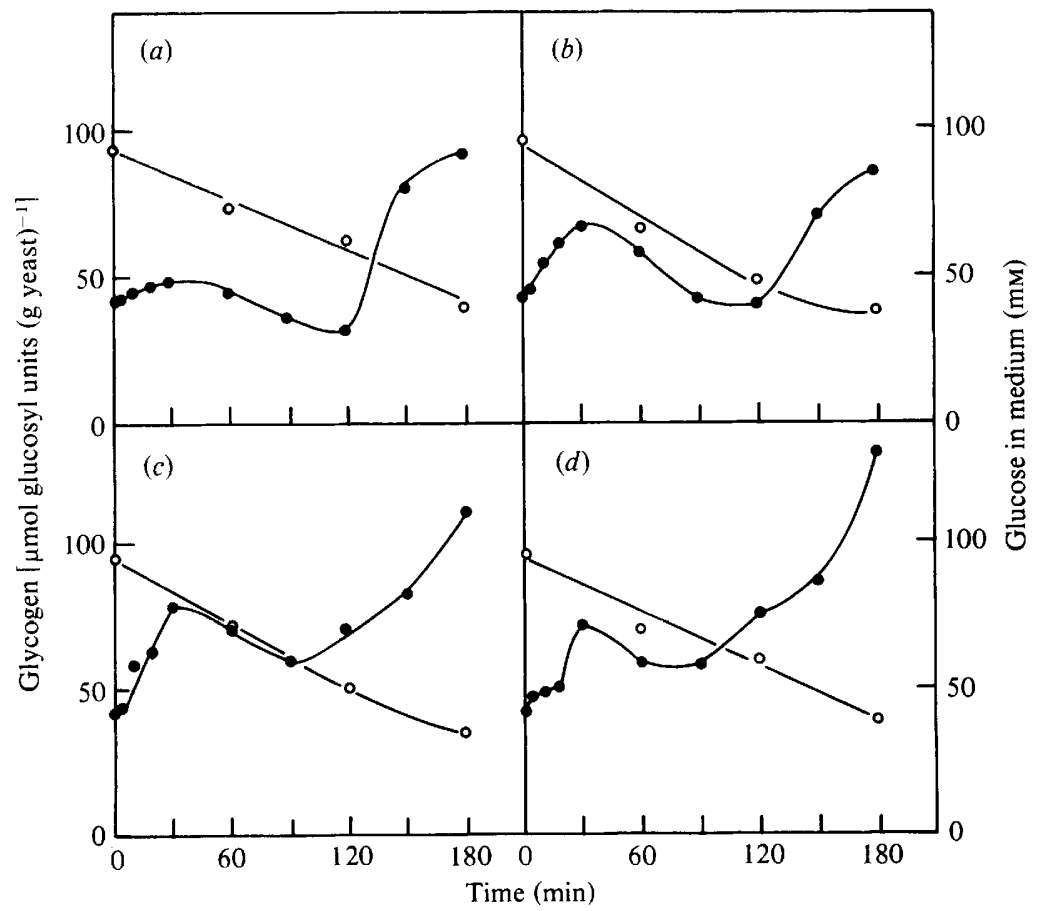

Fig. 3. Glycogen metabolism in $S$. carlsbergensis cells in the presence of various amino acid mixtures. The cells were incubated in basic medium with the amino acids specified (concentrations in $\mathrm{g} \mathrm{l}^{-1}$ ). $(a)$ Asp, 0.08; Asn, 0.1; Glu, 0.3; Gln, 0.17; Lys, 0.19. (b) Leu, 0.19; Ile, 0.12; His, 0.07; Met, 0.06; Val, 0.11. (c) Phe, 0.11; Tyr, 0.15; Trp, 0.04; Thr, 0.05; Ala, 0.07. (d) Ser, 0.07; Arg, 0.09; Pro, 0.17; Gly, 0.06. Gly cogen in cells; $O$, glucose in medium. 
$50 \mathrm{mM}$-asparagine maintained a constant level of glycogen for about $30 \mathrm{~min}$. Without preincubation and with all the other amino acids, glycogen was synthesized initially at a low rate for 30-60 min; then breakdown occurred. Cell growth was apparent by bud formation after 1-2 $\mathrm{h}$ and an increase in $A_{546}$.

The above experiments demonstrated that the presence of nitrogen sources supporting growth was not sufficient to induce immediate glycogen breakdown as was peptone. This could be due to two possibilities: peptone contains some substances responsible for the effect, or peptone acts immediately because it is composed of all amino acids necessary for immediate cell proliferation. While the first possibility is more difficult to prove, the second could be tested simply by adding to the cells a defined mixture of amino acids in the molar ratio found in casein (Mercier et al., 1971), from which the peptone is derived. As shown in Fig. 2, a $0.22 \%$ mixture of amino acids indeed mimicked the effects of peptone. This experiment did not rule out the possibility that a single amino acid not tested in the previous experiments may have been responsible for this result. In order to identify the amino acid(s) responsible for the induction of glycogen breakdown, amino acids were added in groups in the same concentration as in the total mixture (Fig. $3 a-d)$ ). Group (a) contained those most easily utilized as a nitrogen source, while in group $(d)$ those serving as poor sources were combined (Suomalainen \& Oura, 1971). With all four mixtures, glycogen was initially synthesized for about $30 \mathrm{~min}$, followed by a degradation period. After $90 \mathrm{~min}$, resynthesis of glycogen occurred. The $A_{546}$ and the number of budding cells increased after $120-180 \mathrm{~min}$ in all these experiments, indicating growth of the cells. With the more easily utilized nitrogen sources, the initial glycogen synthesis rate was lower, indicating that glycogen synthesis was the result of a lack of nutrients (Lillie \& Pringle, 1980) at least as perceived by the cells prior to induction of enzymes enabling them to interconvert certain amino acids. These experiments showed that no single amino acid was able to trigger glycogen breakdown, but that it was initiated only if all necessary amino acids were supplied. One can assume that in the presence of only a few amino acids or ammonium ions as nitrogen sources, the enzymes necessary for synthesis of the lacking amino acids must be induced prior to growth, although this was not measured. Only after the induction period (i.e. between $30 \mathrm{~min}$ and $1 \mathrm{~h}$ ) was glycogen breakdown observed.

\section{Response of glycogen metabolism to dinitrophenol}

Still, the question remains, how can cells sense within minutes the simultaneous presence of all amino acids in the nutrient broth? One possibility is that initiation of massive protein synthesis after inoculation draws heavily on the energy pool of the cells, thus initiating glycogen breakdown to make up the deficit. In this case, lowering the energy supply should also initiate glycogen breakdown.

Cells were incubated in complete medium in the presence of the uncoupler dinitrophenol $\left(10^{-4} \mathrm{M}\right)$ with and without glucose. Controls were incubated in complete and basic medium without dinitrophenol. While glycogen breakdown was initiated by peptone, the glycogen level remained constant in the presence of dinitrophenol but in the absence of glucose. However, the uncoupler slowed glycogen synthesis in the presence of glucose, indicating that it was taken up and exerted an influence on cell metabolism. Apparently, increasing the consumption of metabolic energy does not by itself stimulate glycogen breakdown.

\section{The effect of peptone on metabolites}

The above conclusion was substantiated by direct measurement of the adenylate pool and other key intermediates of glycolysis in basic or complete medium. Since the concentration of the intermediates in the cells was too low for exact determination in a $2 \%$ cell suspension, the concentration of the cells was increased to $10 \%(\mathrm{w} / \mathrm{v})$. At this high cell concentration, peptone inhibited glycogen synthesis, but glycogen breakdown was observed only initially. Probably, important amino acids were quickly consumed by the concentrated cell 


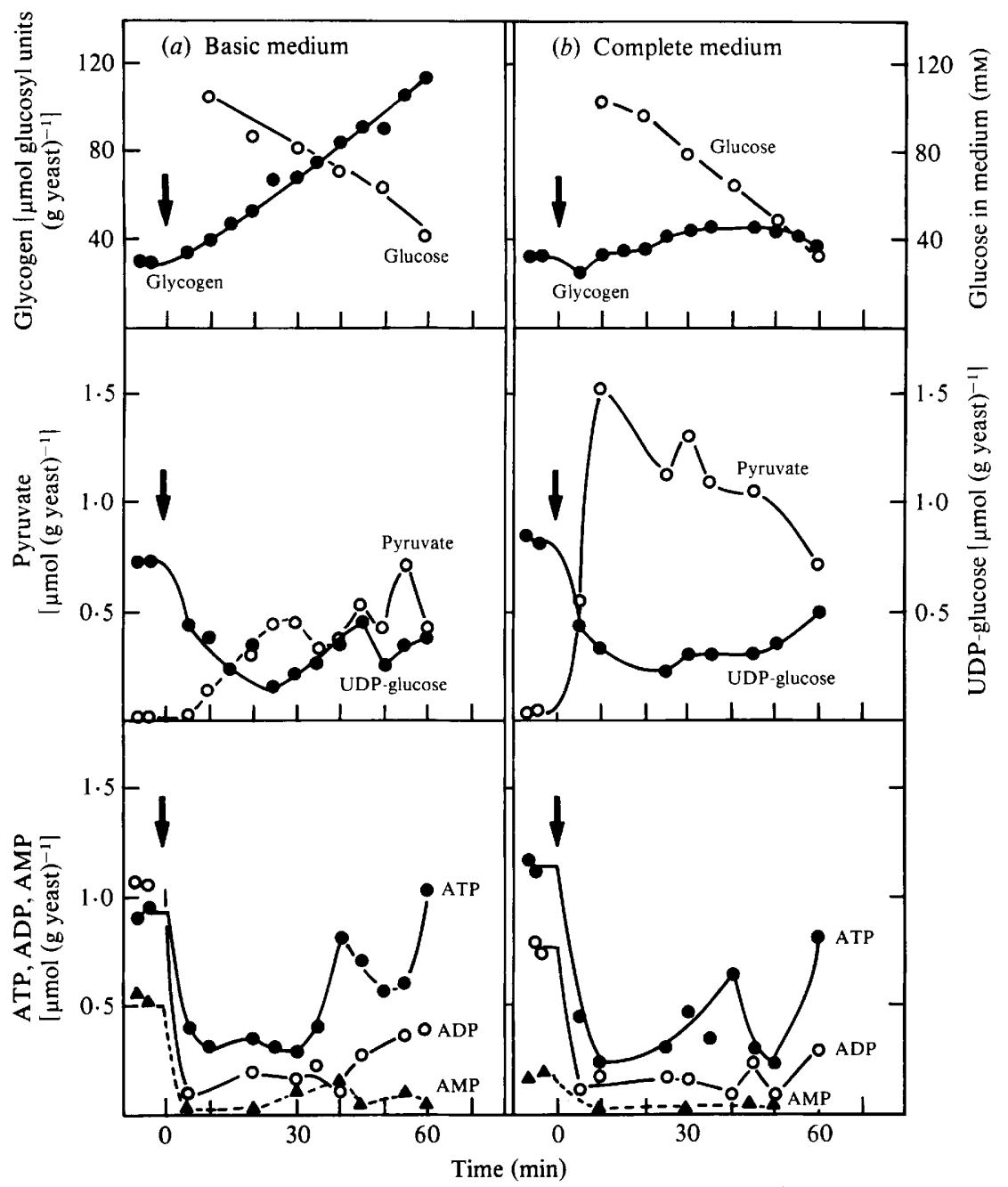

Fig. 4. Glycogen synthesis and metabolite concentrations in $S$. carlsbergensis in the absence $(a)$ and presence $(b)$ of nitrogen sources. A $10 \%$ suspension of cells was prepared in basic $(a)$ or complete $(b)$ medium. Measurements were made of glucose concentration in the medium and of the concentrations of glycogen, pyruvate, UDP-glucose and adenine nucleotides in the cells before and after the addition of glucose (arrows).

suspension, resulting in an insufficient supply of amino acids. Therefore, glycogen breakdown occurred for only a short time. Nevertheless, the suppression of glycogen synthesis was very pronounced in the presence of peptone. One can assume that the change of intermediates in response to peptone should be the same in a less concentrated cell suspension.

A representative experiment is shown in Fig. 4, illustrating the effect of peptone on glycogen synthesis, glucose consumption, the cell contents of pyruvate and UDP-glucose, and adenylate concentration. While glycogen synthesis differed considerably in the presence and absence of peptone, there was little effect of peptone on the levels of the metabolites, all of which followed similar patterns in the absence and presence of peptone, though in the latter case, pyruvate concentration tended to be elevated. This points to an activation of glycolysis, which is also reflected by the higher glucose consumption rate (Fig. $4 b$, top). The behaviour of UDP-glucose was puzzling because as the substrate for glycogen synthase, its concentration should have been lowered during glycogen synthesis, which was not the case. Its concentration varied similarly in the presence and absence of peptone. However, 


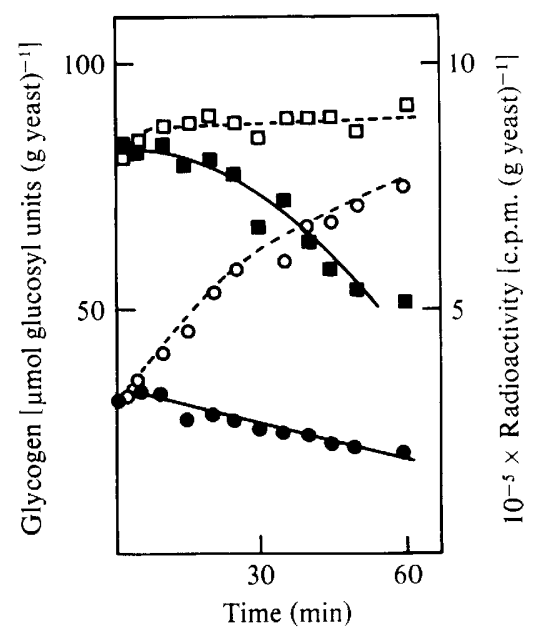

Fig. 5. Turnover of glycogen in $S$. carlsbergensis in the presence of glucose in phosphate buffer. Glycogen $(0,0)$ and radioactivity in glycogen $(\boldsymbol{\square}, \square)$ were measured in cells after transfer from buffer with $\mathrm{D}-\left[\mathrm{U}-{ }^{14} \mathrm{C} / \mathrm{glucose}\right.$ into glucose-free buffer (filled symbols) or buffer containing $100 \mathrm{~mm}$ unlabelled glucose (open symbols).

UDP-glucose serves as the precursor for the synthesis of several molecules, all of which govern its steady-state concentration. It is difficult to assume that any of the key metabolites assayed can serve as a regulatory signal, since their concentrations in the cell were not greatly different in the presence of peptone from those in its absence. The adenine nucleotides showed similar behaviour, with an energy charge (Atkinson, 1970) between 0.59 and 0.69 under both conditions. The sum of the adenylates appeared slightly higher in the cells without nitrogen sources and this may exert some regulatory effect (Knowles, 1977).

\section{Absence of glycogen turnover}

Because glycogen metabolism in $S$. carlsbergensis cells reacted much faster to changes of environmental factors than that in $S$. cerevisiae (strain $\alpha$-S-288 C) when tested under the same conditions, it was possible that glycogen metabolism was not regulated. Thus, flow into and out of glycogen storage may simply follow the law of mass action, resulting in a turnover of glycogen by generation of a futile substrate cycle: glycogen would still be degraded while net synthesis took place. This phenomenon should be especially apparent in yeast cells suspended in phosphate buffer: such cells rapidly accumulate glycogen in the presence of glucose but degrade it as soon as glucose is removed (cf. Becker, 1978; Becker et al., 1979). For detection of the turnover, the cells were initially supplied with radioactive glucose to label the glycogen. The radioactive glucose was subsequently removed and the cells were washed and suspended in the presence or absence of unlabelled glucose. Glycogen concentration and radioactive label incorporated in glycogen were measured (Fig. 5). The results showed clearly that glycogen breakdown was completely stopped in the presence of external glucose: i.e. no turnover of glycogen took place, as already demonstrated by Rothman \& Cabib (1969) in $S$. cerevisiae under different conditions. In the control, radioactively labelled glucose was broken down, which proved that the loss of radioactive glucose could be measured under the experimental conditions.

This result points to a highly effective regulation of glycogen breakdown, although at present no obvious mechanism by which it was achieved can be suggested. Yeast phosphorylase is known to be regulated by phosphorylation and dephosphorylation (Fosset et al., 1971; Becker et al., 1981). However, the specific molecular activity of phosphorylase was only correlated with the growth phase of the batch culture, while extracts from cells 
degrading or synthesizing glycogen showed identical phosphorylase activities (Becker, 1982). The very similar pattern of metabolites in the presence and absence of peptone did not yield information for a simple regulatory mechanism mediated by these effectors via allosteric interaction with regulatory enzymes.

As in the case of glycogen synthesis, where the cells start to accumulate the polysaccharide prior to depletion of glucose (Rothman \& Cabib, 1969) or other nutrients (Becker et al., 1979; Lillie \& Pringle, 1980), the signal for glycogen breakdown, which must relay complex information concerning the nutrient level, is not known. The behaviour of the cells resembles the stringent response of bacteria to starvation (Bridger \& Paranchych, 1979), which is mediated by pleiotropic nucleotides and which also affects glycogen metabolism (Dietzler \& Leckie, 1977). Such a mechanism, however, has not yet been shown in eukaryotes and will be difficult to prove unless suitable mutants are found.

The authors thank Dr W. Nader for stimulating discussions and Dr Tom Buckhout for critical reading of the manuscript. The work was supported by the Deutsche Forschungsgesellschaft. M. I. Shehata (on leave from the Faculty of Agriculture, El-Zagazig University, Egypt) and S. M. Mizani were recipients of fellowships of the Heinrich-Hertz-Stiftung and the Deutscher Akademischer Austauschdienst, respectively.

\section{REFERENCES}

AtKinson, D. E. (1970). Enzymes as control elements in metabolic regulation. In The Enzymes, vol. 1, pp. 461-489. Edited by P. D. Boyer. New York \& London: Academic Press.

BECKER, J. U. (1978). A method for glycogen determination in whole yeast cells. Analytical Biochemistry 86, 56-64.

BECKER, J. U. (1982). Mechanisms of regulation of glycogen phosphorylase activity in Saccharomyces carlsbergensis. Journal of General Microbiology 128, $447-454$.

Becker, J. U., VohmanN, H. J. \& Eilers-König, C. (1979). Glycogen metabolism in resting and growing cells of Saccharomyces carlsbergensis. Archives of Microbiology 123, 143-149.

Becker, J. U., Wingender-Drissen, R. \& Pohlig, G. (1981). Yeast phosphorylase phosphatase and -kinase. Biochemical Society Transactions 9, 242.

Bergmeyer, H. U. (editor) (1974). Methoden der enzymatischen Analyse, 3rd edn, vols I \& II. Weinheim: Verlag Chemie.

BRIDGeR, W. A. \& PARANCHYCH, W. (1979). Guanosine tetraphosphate: coordinator of metabolic response to nitrogen starvation in enterobacteria. Trends in Biochemical Sciences 4, 176-179.

Dietzler, D. N. \& Leckie, M. P. (1977). Regulation of ADP glucose synthetase, the rate-limiting enzyme of bacterial glycogen synthesis, by the pleiotropic nucleotides pp-G-pp and ppp-G-pp. Biochemical and Biophysical. Research Communications 77, 1459-1467.

Fonzi, W. A., Shanley, M. \& Opheim, D. J. (1979). Relationship of glycolytic intermediates, glycolytic enzymes and ammonia to glycogen metabolism during sporulation in the yeast Saccharomyces cerevisiae. Journal of Bacteriology 137, 285-294.

Fosset, M., Muir, L. W., Nielsen, L. D. \& Fischer, E. H. (1971). Purification and properties of yeast phosphorylase $a$ and $b$. Biochemistry 10, 41054113.

Gosh, A., Charlampous, F., Sison, Y. \& Borer, R. (1960). Metabolic functions of myo-inositol. Journal of Biological Chemistry 235, 2522-2528.

KNOWLES, C. J. (1977). Microbial metabolic regulation by adenine nucleotide pools. Symposia of the Society for General Microbiology 27, 241-283.

KüENZI, M. T. \& FIECHTER, A. (1972). Regulation of carbohydrate composition of Saccharomyces cerevisiae under growth limitation. Archiv für Mikrobiologie 84, 254-265.

Lillie, S. H. \& Pringle, J. R. (1980). Reserve carbohydrate metabolism in Saccharomyces cerevisiae: responses to nutrient limitation. Journal of Bacteriology 143, 1384-1394.

Mercier, J. C., Grosclaude, F. \& RibadeauDUMAS, B. (1971). Structure primaire de la caséine $\alpha_{\mathrm{s} 1}$-bovine: sequence complète. European Journal of Biochemistry 23, 41-51.

Rothman, L. B. \& CABIB, E. (1969). Regulation of glycogen synthesis in the intact yeast cell. Biochemistry 8, 3332-3341.

Suomalainen, H. \& Oura, E. (1971). Yeast nutrition and solute uptake. In The Yeasts, vol. II, pp. 3-74. Edited by A. H. Rose \& J. S. Harrison. London \& New York: Academic Press. 